\title{
Synthesis and Some Properties of Metal Organic Chemical Vapour Deposited Lithium Chromium Oxide Thin Films
}

\author{
G. O. Egharevba \\ Department of Chemistry, Obafemi Awolowo University, Ile - Ife, Nigeria \\ M. A. Eleruja \\ Department of Physics, Obafemi Awolowo University, Ile - Ife, Nigeria
}

O. Osasona

Department of Electronic and Electrical Engineering

Obafemi Awolowo University, Ile - Ife, Nigeria

O. O. Akinwunmi \& B. Olofinjana

Department of Physics, Obafemi Awolowo University, Ile - Ife, Nigeria

C. Jeynes

Department of Electronics and Electrical Engineering

University of Surrey Guildford, Surrey GU2 7XH, UK

E. O. B. Ajayi

Department of Physics, Obafemi Awolowo University, Ile - Ife, Nigeria

Tel: 234-803-666-5500Ｅ-mail: eajayi@oauife.edu.ng

Received: August 22, 2011 Accepted: September 8, 2011 Published: January 1, 2012

doi:10.5539/jmsr.v1n1p130

URL: http://dx.doi.org/10.5539/jmsr.v1n1p130

\begin{abstract}
Thin Films of Lithium Chromium Oxide were deposited on soda lime glass substrates at a temperature of $420{ }^{\circ} \mathrm{C}$ by the pyrolysis of a mixture of Lithium Hydroxide and Chromium Acetylacetonate (1:2), using Metal Organic Chemical Vapour Deposition technique. The prepared thin films were characterized by using Rutherford Backscattering (RBS), X-Ray Diffraction (XRD) and Ultraviolet-Visible Spectrophotometry. Using RBS the ratio of $\mathrm{Li}: \mathrm{Cr}: \mathrm{O}$ in the prepared thin films was found to be $36: 18: 46$, leading to a stoichiometry of $\mathrm{Li}_{2} \mathrm{CrO}_{2+\delta}(\delta=$ 0.5). A direct allowed bandgap of $3.58 \mathrm{eV}$ was obtained from the UV-Visible spectrum, with a blank soda lime glass substrate in the path of the reference beam.
\end{abstract}

Keywords: Precursor, Substrate, Spectrum, Wavelength, Band gap

\section{Introduction}

Alkali transition metal oxides have attracted a lot of attention for a long time because of their scientific and technological importance. The applications range from electrochromism in smart windows to electrochemical properties in micro batteries as well as high density batteries (Mizushima, Jones, Wiseman, \& Goodenough, 1980). Electrochromic materials have the ability to change their colour from nearly or fully dark colour to near or full transparency with the aid of an applied potential. Inorganic transition metal oxides exhibit electrochromism and can quite easily be deposited as thin films, which is appropriate for device technology 
(Larsson \& Niklasson, 2004). Inorganic transparent electrodes in the form of transition metal oxide thin films are used as electrochromic displays (ECD's) in preference to polymers (Nagai \& Morisaki, 2003).

$\mathrm{CrO}_{2}$ is metastable at atmospheric pressure and if heated, easily decomposes into the insulating antiferromagnetic form. $\mathrm{Cr}_{2} \mathrm{O}_{3}$ compound is the most stable chromium oxide at ambient conditions (Stanoi et al., 2005). The optical switching is easily performed by the insertion or extraction of electrons together with ions such as $\mathrm{H}^{+}, \mathrm{Li}^{+}, \mathrm{Na}^{+}$and $\mathrm{K}^{+}$, where small ions are best needed (Larsson \& Niklasson, 2004). Indeed, the insertion of lithium, sodium and other metals into transition metal oxide matrix has been used to modify or improve the various properties of the oxides particularly for electrochromic use and lithium batteries (Cogan et al., 1997). Some of these materials which have been prepared by various researchers include: Lithium chromate (Cogan et al., 1997), Vanadium bronzes of $\mathrm{Li}_{\mathrm{x}} \mathrm{V}_{2} \mathrm{O}_{5}$ (Delmas, Brethes, \& Menetrier, 1991); Co-V-O, Cr-V-O thin films (Adedeji, Egharevba, Jeynes, \& Ajayi, 2002); Li-Co-O, Na-Ni-O, Na-Co-O (Eleruja, 1998); LiNiO (Eleruja et al., 2007); $\mathrm{M}_{\mathrm{x}} \mathrm{WO}_{3}(\mathrm{M}=\mathrm{H}, \mathrm{Li}$, Na or K) (Rowleley \& Mortimer, 2002); LiMoO thin films (Ilori et al., 2005). Preparation techniques such as sputtering (Larsson \& Niklasson, 2004; Fan, 1978), metal organic chemical vapour deposition (Adedeji, Egharevba, Jeynes, \& Ajayi, 2002; Eleruja, 1998; Eleruja et al., 2007; Ilori et al., 2005), electrochemical deposition (Díaz-Carrasco, Moreau, Guyomard, Kuhn, \& García-Alvarado, 2006) among others, have been employed to prepare these films.

In this paper, we report the preparation of lithium chromium oxide thin films from the pyrolysis of a mixture of lithium hydroxide and chromium acetylacetonate and the results of the investigations of some basic properties of the deposited thin films.

\section{Experimental Procedure}

\subsection{Thin Film Preparation}

The cleaning procedure reported earlier (Ajayi, 1970) was used to clean the substrates and other glass wares. Prior to each deposition, the substrates, the stainless steel blocks and the reaction chamber were scrubbed thoroughly using: detergent, distilled water, trichloroethylene, acetone, ethyl alcohol and distilled water respectively to dislodge the dirt on the glass, to ensure that hydrocarbon and grease were removed from the substrate and also to ensure that the substrate surfaces were free from surface contamination and defects.

The thin films of lithium chromium oxide were prepared using the pyrolytic method of metal organic chemical vapour deposition which had been reported previously (Ajayi, 1970). The set up for the deposition is shown in Figure 1. The precursor, a mixture of lithium hydroxide and chromium acetylacetonate (in ratio 1:2), was grounded thoroughly in a mortar. The fine powder of the precursor was poured into an unheated receptacle and nitrogen gas (passed through calcium chloride pellets as drying agent) was blown through the precursor at a rate of $2.5 \mathrm{dm}^{3} / \mathrm{min}$. The nitrogen-borne precursor was transported into the hot chamber kept at $420{ }^{\circ} \mathrm{C}$ by an electrically heated furnace. In the hot zone, the precursor first sublimed before the thermal decomposition, resulting in the coating of the substrates. The process was left on for an hour at the deposition temperature of 420 ${ }^{\circ} \mathrm{C}$. The whole process was carried out in a fume hood, to minimize some of the handling problems associated with such compound.

\subsection{Characterization of Lithium Chromium Oxide Thin Films}

The compositional analysis of the thin films and the blank sodalime substrate were carried out using the Rutherford Backscattering Spectroscopy (RBS). This was done using a 2 MV Tandetron accelerator which involve the use of $1.5 \mathrm{MeV}{ }^{4} \mathrm{He}^{+}$. The detector scattering angle was $147.7^{\circ}$ with solid angle $3.5 \mathrm{msr}$. The spectrum was obtained under normal condition (angle of incidence $\theta_{1}=0^{\circ}$ and the angle of emergence $\theta_{2}=180^{\circ}$ ) with a beam current that is less than $15 \mathrm{nA}$ and nominal beam size (normal incidence) of $1 \mathrm{~mm}$. Depth profile was extracted automatically using the IBA DataFurnace software developed at the university of Surrey, Surrey, UK.

Absorbance measurements were carried out to study the optical behaviour of the thin films in the UV-visible range, using a Unicam SP8-400 UV-visible Spectrophotometer. All measurements were made with a blank soda-lime glass substrate in the reference beam. The X-ray diffraction pattern of the lithium chromium oxide thin films was obtained using MD10 mini Diffractometer for an exposure time of 1200 seconds using $\mathrm{CuK}_{\alpha}$ radiation $(\lambda=0.15418 \mathrm{~nm})$.

\section{Results and Discussion}

\subsection{Thin Films}

Films of good uniformity and adherence were obtained at the deposition temperature of $420{ }^{\circ} \mathrm{C}$. The films showed good adhesive ability when subjected to scotch tape test. Below this temperature, the films obtained were thin and also show poor adherence property. 


\subsection{Compositional Study}

IBA DataFurnace was used to fit the RBS data with elemental depth profiles. Figure 2(a) shows the RBS spectrum of Li-Cr-O thin films on Soda-lime glass substrate. The surface glass is spurious while the $\mathrm{Li}-\mathrm{Cr}-\mathrm{O}$ is probably oxidised at the surface. The oxygen signal could be seen and there were no charging artefacts, so the inferred lithium signal is good. A mismatch was observed between the experimental data and the data fit at channel 200. This is as a result of charging effect from the substrate. The spectrum indicates a good fit and using DataFurnace Code (Jeynes et al., 2003), the ratio of Li:Cr:O was estimated to be 36:18:46 leading to stoichiometry of $\mathrm{Li}_{2} \mathrm{CrO}_{2+\delta}(\delta=0.5)$. It was also observed that the ratio of $\mathrm{Li}: \mathrm{Cr}$ in the thin films confirmed our earlier reports on vanadium cobalt oxide systems (Adedeji, Egharevba, Jeynes, \& Ajayi, 2002) and lithium nickel oxide (Eleruja et al., 2007) that the Li:Cr ratio in the precursor is different from that in the film. In our earlier reports, we attributed this difference to the possible reconstitution of the structure and bonds at the formation stage of the films.

Figure 2(b) shows the depth profiling of the combined film and soda-lime glass substrate. The profile shows that there is diffusion of some materials across the film-substrate interface. This feature had been observed in many thin film systems (Eleruja et al., 2007; Ajayi, Akanni, Lambi, Jeynes, \& Watts, 1990), where different elements migrated from the substrates to the films.

\subsection{X-Ray Diffraction}

The X-Ray Diffraction pattern of the lithium chromium oxide thin film is shown in Figure 3. The presence of diffraction peaks shows that the thin films are polycrystalline. The diffraction peaks appear at diffraction angle, $2 \theta=10.84,13.12,13.25,16.54,21.21,23.50,30.45,31.65,33.98$ and $36.88^{\circ}$. The diffraction pattern does not match the available patterns of lithium chromates. However, the peak at $10.84^{\circ}$ correspond to (010) plane of $\mathrm{Cr}_{2} \mathrm{O}_{5}$ (Card Number 36-1329), 13.12 ${ }^{\circ}$ to (110) plane of $\mathrm{Li}_{2} \mathrm{CrO}_{4}$ (Card Number 31-0715), $13.25^{\circ}$ to (011) plane of $\mathrm{Cr}_{2} \mathrm{O}_{5}$ (Card Number 36-1329), $16.54^{\circ}$ to (100) plane of $\mathrm{Li}_{3} \mathrm{CrO}_{4}$ (Card Number 45-0347), 21.21 ${ }^{\circ}$ to (011)

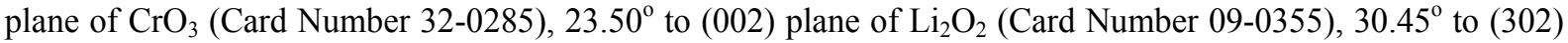
plane of $\mathrm{Cr}_{2} \mathrm{O}_{5}$ (Card Number 36-1329), 31.65 to (122) plane of $\mathrm{Cr}_{5} \mathrm{O}_{12}$ (Card Number 18-0390), 33.98 to (104) plane of $\mathrm{Cr}_{2} \mathrm{O}_{3}$ (Card Number 38-1479), 36.88o to (101) plane of $\mathrm{CrO}_{2}$ (Card Number 43-1040). This is due to the fact that the prepared thin films are non-stoichiometry in nature (as confirmed by the RBS) and hence the structure is different from those of any particular lithium chromates.

\subsection{Absorbance Measurements}

Figure 4a shows a plot of absorbance against incident photon wavelength at normal incidence and at room temperature for the MOCVD lithium chromium oxide thin films deposited on sodalime glass substrate. The as-deposited samples show high absorbance in the region $330-340 \mathrm{~nm}$ with a decrease at $370-420 \mathrm{~nm}$. This indicates that the film is highly absorbing in the ultraviolet region of the spectrum. This may be the result of light scattering from the micrometer sized grains of the films. Such observation in the $\mathrm{MoO}_{3}$ thin films deposited via chemical vapour deposition (CVD) was attributed to the defects in the films (Ivanova, et al., 2007).

Reflectance, $R$ of thin films was calculated from the equation (Cheng, Gomi, \& Sakata, 1996):

$$
R=1-\sqrt{\frac{T}{\exp (-\alpha d)}} .
$$

Where $T$ is transmittance, $\alpha$ is the absorption coefficient and $d$ is the thickness of the film. The refractive index, $\mathrm{n}$ was calculated from the equation (Cheng, Gomi, \& Sakata, 1996):

$$
n=\frac{\left(1+R^{1 / 2}\right)}{\left(1-R^{1 / 2}\right)} .
$$

Figures $4 \mathrm{~b}$ shows the plot of the reflectance and as a function of wavelength for as-deposited films. The refractive index of a solid in thin film form gives information on the electronic polarizability and local field. It is also used for determining the density of colors inside the material (Galakhov et al., 1995). Reflectance, R and refractive index, $\mathrm{n}$ of the films decrease rapidly to approach constant values at long wavelengths. The long wavelength value of the refractive index of the film is $3.50 \pm 0.3$.

The absorption coefficient $\alpha$ and the optical band gap $E_{g}$ for the lithium chromium oxide thin films were determined from the optical absorbance data using equation 3 (Tauc, 1974), 


$$
\alpha=\frac{1}{d} \ln \frac{1}{T} .
$$

where $T$ is the transmittance and $d$ is the film thickness. The estimated film thickness from RBS was $200 \mathrm{~nm}$. Optical characterization constitutes the most direct and perhaps the simplest approach for probing the band structure of the deposited films, as a result, the optical band gap was determined using the following Tauc relation for band-to-band transition (Tauc, 1974):

$$
\alpha(v)=A\left(h v-E_{g}\right)^{n^{\prime}}
$$

$A$ is a constant different for different types of transition, indicated by the value of $n^{\prime}$, for allowed direct gap transition, $n^{\prime}=1 / 2$. From the curve $\alpha^{2}$ versus $h v$ (Figure 4c), $E_{g}$ was determined by extrapolating the linear part of the plot to line $\alpha^{2}=0$. The calculated value of the optical band gap energy for the prepared lithium chromium oxide thin film is $3.58 \mathrm{eV}$ for direct allowed transition. The edge at $3.35 \mathrm{eV}$ does not correspond to the band edge as the absorption in that region is not as a result of band to band transition but due to scattering of light by the microcrystalline particles of the material. It has been reported that the optical band gap energy of $\mathrm{Cr}_{2} \mathrm{O}_{3}$ film is in the range of $4.7-5 \mathrm{eV}$ (Hong, Kim, Kim, Sung, \& No, 1997). The value obtained for lithium chromium oxide thin films $(3.58 \mathrm{eV})$ in this work is lower than the band gap energy obtained by Hong et al., (1997). The lowering of the band gap may be attributed to the presence of lithium in the chromium oxide matrix. The optical band gap is a basic property of optical materials. The measured band gap depends not only on the material but also on its other characteristics such as crystallinity and stoichiometry (Hong et al., 1997). It may also depend on the design variables of the MOCVD apparatus, deposition temperature and the flow rate of the carrier gas (Olofinjana et al., 2010).

\section{Conclusion}

Thin films of Lithium Chromium Oxide have been deposited on soda lime glass substrates at a temperature of $420{ }^{\circ} \mathrm{C}$ by the pyrolysis of a mixture of Lithium Hydroxide and Chromium Acetylacetonate (1:2), using Metallorganic Chemical Vapour Deposition technique. The prepared thin films were characterized by using Rutherford Backscattering (RBS), X-Ray Diffraction (XRD) and Ultraviolet- Visible Spectrophotometry. Using $\mathrm{RBS}$, the ratio of Li:Cr:O in the prepared thin films was found to be 36:18:46, leading to a stoichiometry of $\mathrm{Li}_{2} \mathrm{CrO}_{2+\delta}(\delta=0.5)$. A direct allowed band gap of $3.58 \mathrm{eV}$ was obtained from the UV-Visible spectrum, taken with a blank soda lime glass substrate in the path of the reference beam.

\section{Reference}

Adedeji, A. V., Egharevba, G. O., Jeynes, C., \& Ajayi, E. O. B. (2002). Preparation and Characterization of Pyrolytically Deposited (Co-V-O and Cr-V-O) Thin Films. Thin Solid Films, 402, 49-54. http://dx.doi.org/10.1016/S0040-6090(01)01602-9

Ajayi, O. B. (1970). Electrical and Optical Properties of Pyrolytically Deposited Indium Oxide Thin Films. M.Sc. Thesis, Urbana Illinois, USA.

Ajayi, O. B., Akanni, M. S., Lambi, J. N., Jeynes, C., \& Watts, J. F. (1990). Compositional Studies of Various Metal Oxide Coatings on Glass. Thin Solid Films, 185, $123-136$. http://dx.doi.org/10.1016/0040-6090(90)90012-3

Cheng, C. S., Gomi, H., \& Sakata, H. (1996). Electrical and Optical Properties of $\mathrm{Cr}_{2} \mathrm{O}_{3}$ Films Prepared by Chemical Vapour Deposition. Physica Status Solidi (a), 155, 417-425. http://dx.doi.org/10.1002/pssa.2211550215

Cogan, S. F., Rauh, R. D. Klein, J. D., Nguyen, N. M. Jones, R. B., \& Plante, T. D. (1997). Variable Transmittance Coatings Using Electrochromic Lithium Chromate and Amorphous $\mathrm{WO}_{3}$ Thin Films. Journal of Electrochemical Society, 144, 956-960. http://dx.doi.org/10.1002/chin.199726279

Delmas, C., Brethes, S., \& Menetrier, M. (1991). $\omega-\mathrm{LixV}_{2} \mathrm{O}_{5}-\mathrm{A}$ New Electrode Material for Rechargeable Lithium Batteries. Journal of Power Sources, 34, 113-118. http://dx.doi.org/10.1016/0378-7753(91)85030-Z

Díaz-Carrasco, P., Moreau, P., Guyomard, D., Kuhn, A. \& García-Alvarado, F. (2006). Electron energy Loss Spectroscopy Analysis of Lithium Deintercalated $\mathrm{Li}_{5 / 3-x} \mathrm{Ti}_{7 / 3} \mathrm{CrO}_{7}$. Journal of Physics and Chemistry of Solids, 67, 1295-1298. http://dx.doi.org/10.1016/j.jpcs.2006.01.060 
Eleruja, M. A. (1998). Preparation and Characterization of Metallorganic Chemical Vapor Deposited (MOCVD) Mixed Metal Oxide $\left(\mathrm{A}_{\mathrm{x}} \mathrm{M}_{1-\mathrm{x}} \mathrm{O} ; \mathrm{A}=\mathrm{Li}, \mathrm{Na} ; \mathrm{M}=\mathrm{Ni}, \mathrm{Co}\right)$ Thin Films from Single Solid Source Precursor, Ph.D. Thesis, Obafemi Awolowo University, Ile-Ife, Nigeria, (Unpublished).

Eleruja, M. A., Egharevba, G. O. Abulude, O. A., Akinwunmi, O. O. Jeynes, C., \& Ajayi, E. O. B. (2007). Preparation and Characterization of Metalorganic Chemical Vapor Deposited Nickel Oxide and Lithium Nickel Oxide Thin Films. Journal of Materials Science, 42, 2758-2765. http://dx.doi.org/10.1007/s10853-006-1405-9

Fan, J. C. C. (1978). Selective-Black Absorbers Using Sputtered Cermet Films. Thin Solid Films, 54, 139-148. http://dx.doi.org/10.1016/0040-6090(78)90190-6

Galakhov, V. R., Kurmaev, E. Z., St. Uhlenbrock, Neumann, M., Kellerman, D. G. \& Gorshkov, V. S. (1995). Electronic Structure of $\mathrm{LiNiO}_{2}, \mathrm{LiFeO}_{2}$ and $\mathrm{LiCrO}_{2}$ : X-Ray Photoelectron and X-ray Emission Study. Solid State Communication, 95(6), 347-351. http://dx.doi.org/10.1016/0038-1098(95)00279-0

Hong, S., Kim, E. Kim, D. W., Sung, T. H., \& No, K. (1997). On Measurement of Optical Band Gap of Chromium Oxide Films Containing both Amorphous and Crystalline Phases. Journal of Non-crystalline Solids, 221, 245-254. http://dx.doi.org/10.1016/S0022-3093(97)00367-0

Ilori, O. O., Osasona, O., Eleruja, M. A., Egharevba, G. O., Adegboyega, G. A., Chiodelli, G., Boudreault, G. Jeynes, C., \& Ajayi, E. O. B. (2005). Preparation and Characterization of Metallorganic Chemical Vapour Deposited $\mathrm{Li}_{\mathrm{x}} \mathrm{Mo}_{\mathrm{y}} \mathrm{O}_{\mathrm{z}}$ Using a Single Source Precursor. Ionics, 11, 387-392. http://dx.doi.org/10.1007/BF02430252

Ivanova, T., Geshava, K. A., Kalitzova, M., Marsen, B., Cole, B., \& Miller, E. L. (2007). Electrochromic Behavior of Mo/W Oxides Related to Their Surface Morphology and Intercalation Process Parameters. Materials Science and Engineering: B, 142, 126-135. http://dx.doi.org/10.1016/j.mseb.2007.06.020

Jeynes, C., Barradas, N. P., Marriott, P. K., Boudreault, G., Jenkin, M., Wendler, E., \& Webb, R. P. (2003). Elemental Thin Film Depth Profiles by Ion Beam Analysis Usinf Simulated Annealing - A New Tool. Journal of Physics D: Applied Physics, 36 R97- R126. http://dx.doi.org/10.1088/0022-3727/36/7/201

Larsson, A. L. \& Niklasson, G. A. (2004). Optical Properties Electrochromic All-Solid-State Devices. Solar Energy Materials and Solar Cells, 84, 351-360. http://dx.doi.org/10.1016/j.solmat.2004.02.051

Mizushima, K., Jones, P. C., Wiseman, P. J., \& Goodenough J. B. (1980). $\mathrm{Li}_{\mathrm{x}} \mathrm{CoO}_{2}(0<\mathrm{x}<-1)$ : A New Cathode Material for Batteries of High density. Materials Research Bulletin, 15, 783-789. http://dx.doi.org/10.1016/0025-5408(80)90012-4

Nagai, J. \& Morisaki, S. (2003). Molecular Properties of Partially Substituted Nickel Oxide Clusters. Solid State Ionics, 165, 149-153. http://dx.doi.org/10.1016/j.ssi.2003.08.026

Olofinjana, B., Egharevba, G. O., Eleruja, M. A., Jeynes, C., Adedeji, A. V., Akinwunmi, O. O., Taleatu, B. A. Mordi, C. U., \& Ajayi, E. O. B. (2010). Synthesis and Some Properties of Metal Organic Vapour Deposited Molybdenum Oxysulphide Thin Films. Journal of Materials Science \& Technology, 26, 552-557. http://dx.doi.org/10.1016/S1005-0302(10)60084-9

Rowley, N. M. \& Mortimer, R. J. (2002). New Electrochromic Materials. Science Progress, 85, 243-262. http://dx.doi.org/10.3184/003685002783238816

Stanoi, D., Socol, G., Grigorescu, C., Guinneton, F., Monnereau, O., Tortet, L., Zhang, T., \& Mihailescu, I. N. (2005). Chromic Oxide Thin Films Prepared and Coated In-Situ with Gold by Pulsed Laser Deposition. Materials Science and Engineering B, 118, 74-78. http://dx.doi.org/10.1016/j.mseb.2004.12.016

Tauc, J. (1974). Amorphous and Liquid Semiconductors. New York, Plenum Press. 


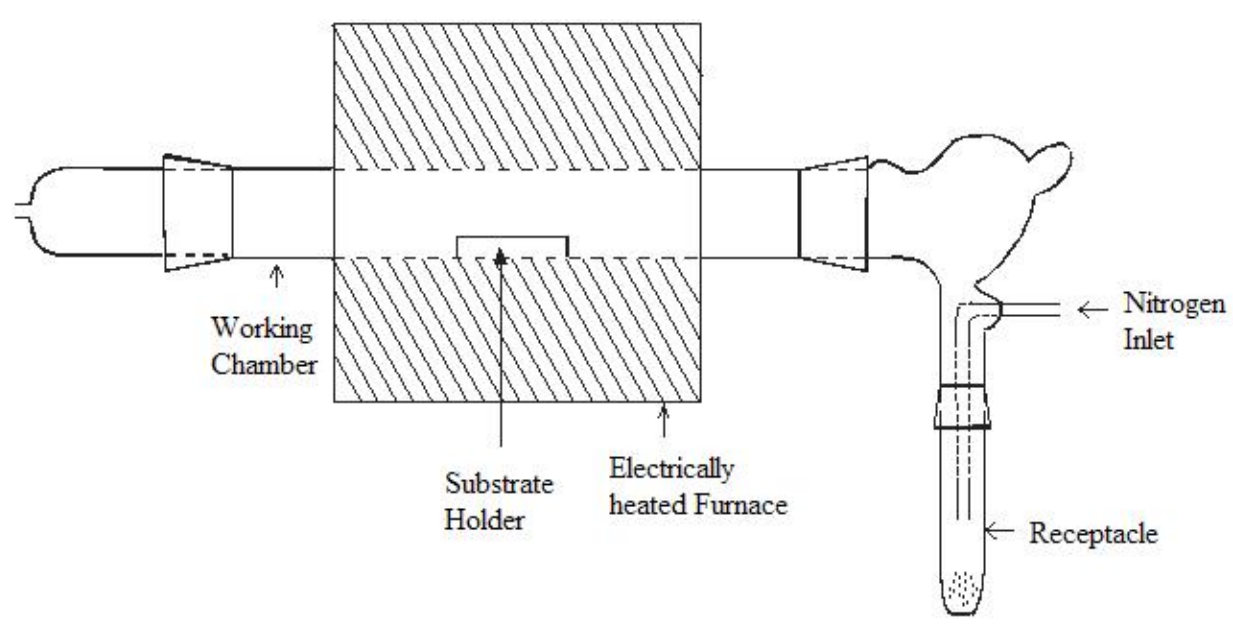

Figure 1. Apparatus for Pyrolysis of the Precursor

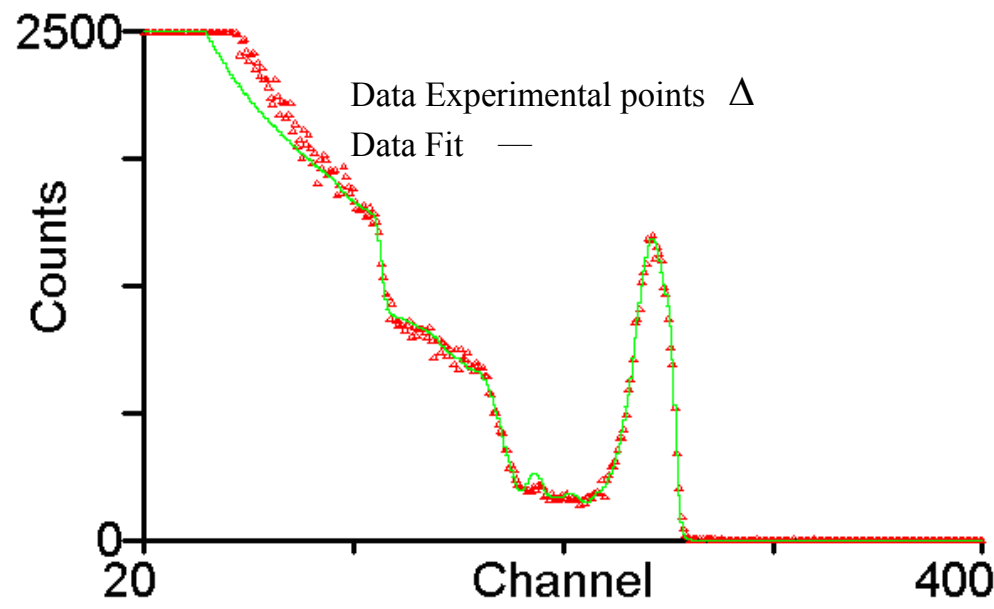

Figure 2(a). RBS Spectrum of the Lithium Chromium Oxide Thin Film

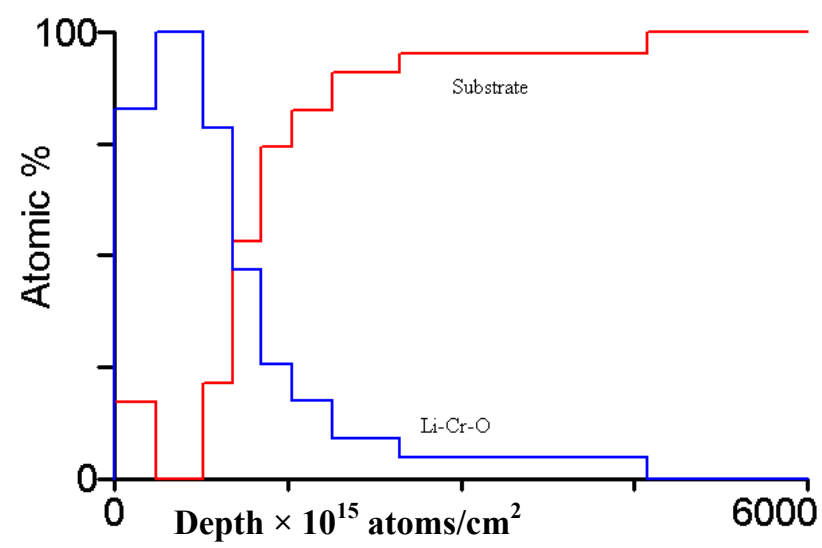

Figure 2(b). Depth Profiling of the Combined Film and Soda-lime Glass Substrate 


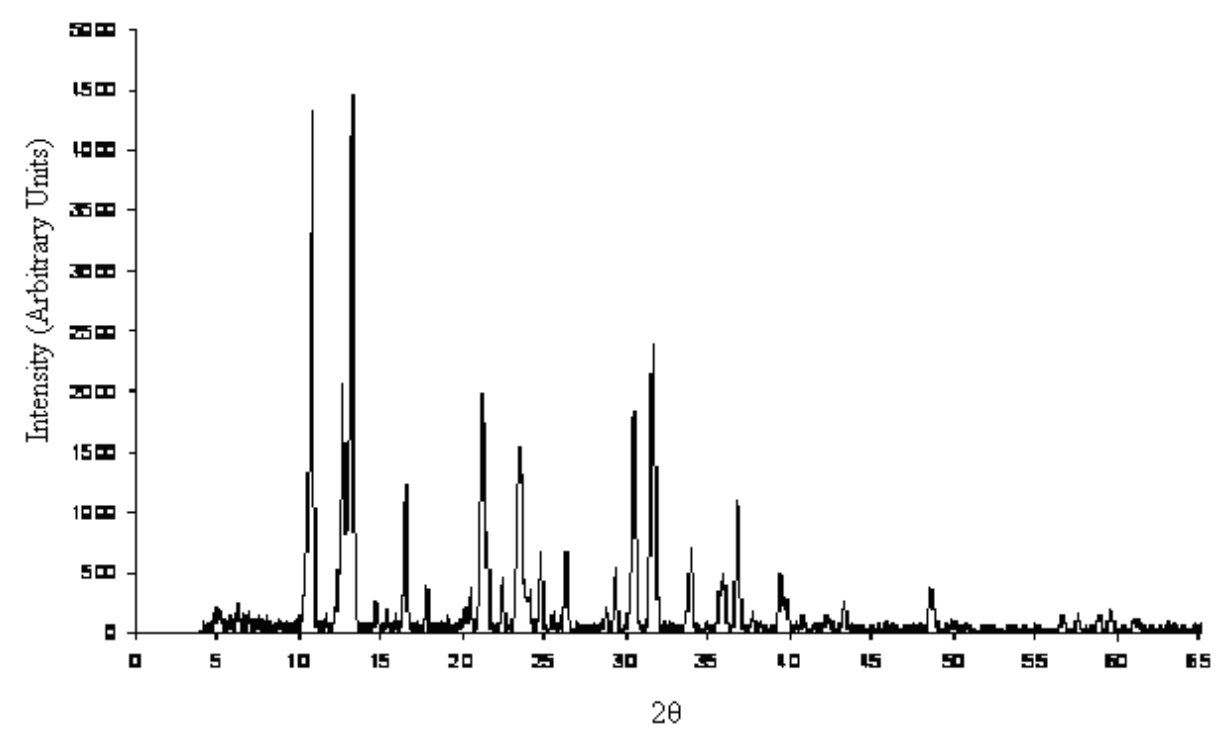

Figure 3. X-Ray diffraction pattern of the Lithium Chromium Oxide thin film

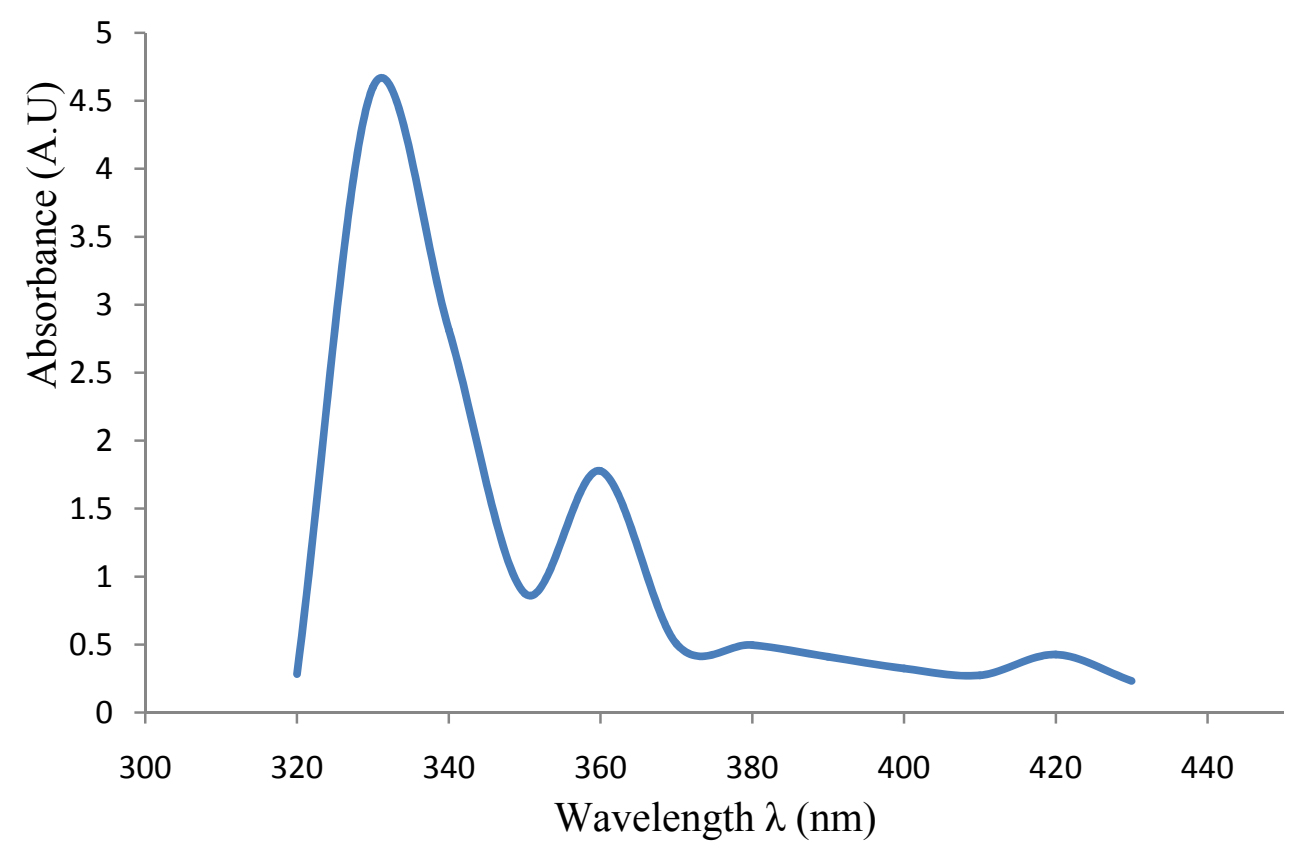

Figure 4(a). Absorbance against wavelength for the Lithium Chromium Oxide thin film 


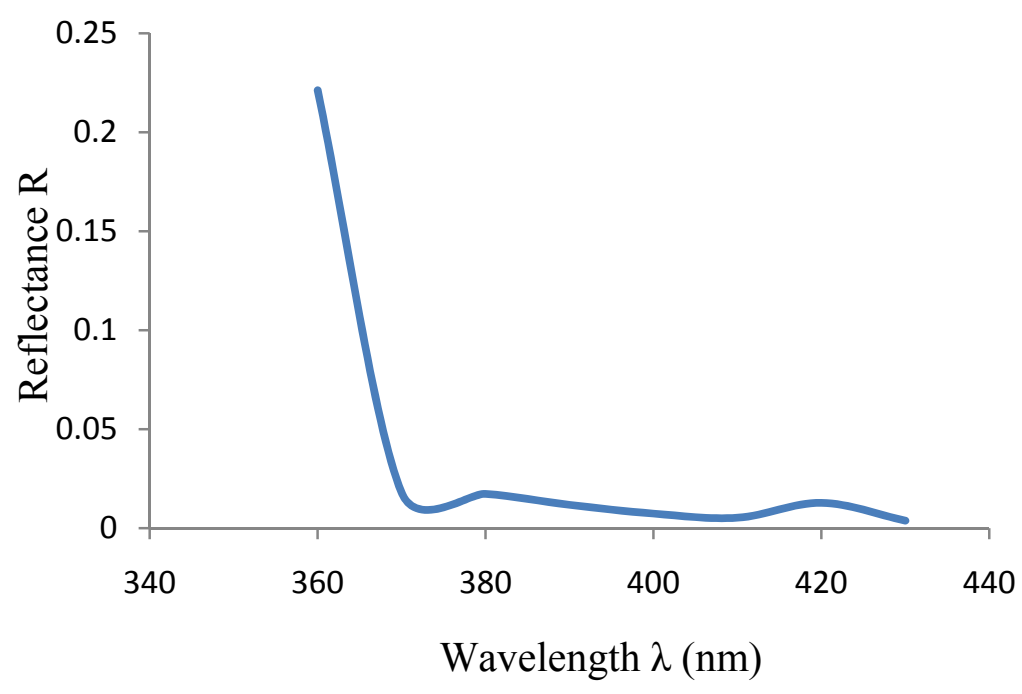

Figure 4(b). Reflectance as a function of wavelength

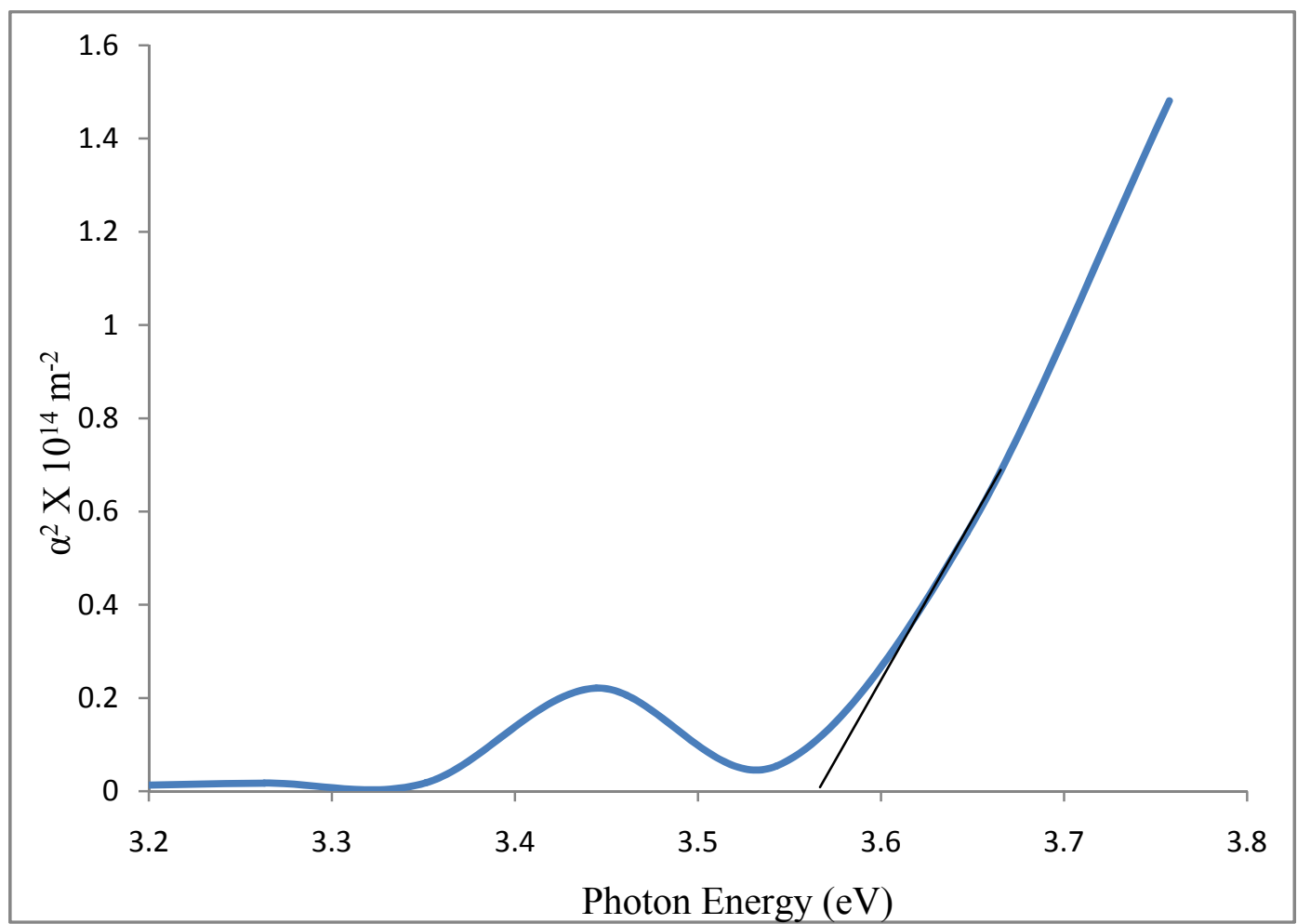

Figure 4(c). A Plot of $\alpha^{2}$ against energy for the Lithium Chromium Oxide thin film 